\title{
Growth Phase Dependent Cell Shape of Haloarcula
}

\author{
Sabine Schwarzer ${ }^{1}$, Marta Rodriguez-Franco ${ }^{2}$, Hanna M. Oksanen ${ }^{3}{ }^{-1}$ and Tessa E. F. Quax ${ }^{1, *}$ \\ 1 Archaeal Virus-Host Interactions, Faculty of Biology, University of Freiburg, Schaenzlestrasse 1, \\ 79104 Freiburg, Germany; sabine.schwarzer@biologie.uni-freiburg.de \\ 2 Cell Biology, Faculty of Biology, University of Freiburg, Schaenzlestrasse 1, 79104 Freiburg, Germany; \\ marta.rodriguez@biologie.uni-freiburg.de \\ 3 Molecular and Integrative Biosciences Research Programme, Faculty of Biological and \\ Environmental Sciences, University of Helsinki, Viikinkaari 9, 00014 Helsinki, Finland; \\ hanna.oksanen@helsinki.fi \\ * Correspondence: Tessa.quax@biologie.uni-freiburg.de; Tel.: +49-761-203-2631; Fax: +49-761-203-2773
}

Citation: Schwarzer, S.; Rodriguez-Franco, M.; Oksanen, H.M.; Quax, T.E.F. Growth Phase Dependent Cell Shape of Haloarcula. Microorganisms 2021, 9, 231. https://doi.org/10.3390/ microorganisms 9020231

Academic Editor: Ricardo Amils Received: 18 December 2020

Accepted: 20 January 2021

Published: 22 January 2021

Publisher's Note: MDPI stays neutral with regard to jurisdictional claims in published maps and institutional affiliations.

Copyright: (c) 2021 by the authors. Licensee MDPI, Basel, Switzerland. This article is an open access article distributed under the terms and conditions of the Creative Commons Attribution (CC BY) license (https:/ / creativecommons.org/licenses/by/ $4.0 /)$.

\begin{abstract}
Several haloarchaea are reported to be pleomorphic, while others exhibit remarkable shapes, such as squares. Recently, Haloferax volcanii was found to alter its morphology during growth. Cells are motile rods in early exponential phase, and immotile plates in stationary phase. It is unknown if this growth phase dependent cell shape alteration is a specific feature of $H f x$. volcanii, or conserved amongst haloarchaea. Here, we studied the cell shape and motility of two haloarchaea species Haloarcula hispanica and Haloarcula californiae. With a combination of light and electron microscopy, we observed that both strains undergo a growth phase dependent morphological development, albeit in a slightly different fashion as Hfx. volcanii. For both Haloarcula strains, the cell size is changing throughout growth. Cell shape seems to be related with motility, as highly motile cells on semi-solid agar plates are predominantly rod-shaped. We conclude that the growth phase dependent cell morphology alteration might be a common feature amongst haloarchaea, and that cell shape is generally linked with a motile life style. The conservation of this phenomenon underscores the importance of studies of the molecular mechanisms regulating cell shape in archaea.
\end{abstract}

Keywords: Haloarcula hispanica; Haloarcula californiae; haloarchaea; pleomorphism; cell shape; motility; archaellum

\section{Introduction}

Microbial cells display great morphological diversity with varying shapes and sizes. Several underlying mechanisms have been discovered determining shape in bacteria and archaea [1-5]. In some species, the shape is uniform in the whole population, while in others this can vary depending on several conditions. The ability of a prokaryotic cell to actively restructure their shape in response to environmental conditions is called morphological plasticity. Pleomorphism describes a phenomenon in which a cellular population adapts its morphology depending on environmental factors or on growth phase.

Several bacterial species like Helicobacter pylori, Legionella pneumophila, Deinococcus radiodurans, and Borrelia burgdorferi are reported to display morphological plasticity depending on environmental conditions [6-9]. Amongst the Archaea, pleomorphism is especially common amongst species belonging to the halophilic Euryarchaea.

Cell morphologies of haloarchaea have been described to range from rods and plates to triangular or even square cells [10-14]. Additionally, the model haloarchaeon Haloferax volcanii (abbr. Hfx volcanii) has been reported to display different cell shapes, including rod-shaped and plate-shaped cells $[12,15,16]$. Recently, improved microscopy techniques for haloarchaea [17], have allowed to study their cell morphology in more detail. Several studies have contributed to mapping the factors that determine cell shape in Hfx. volcanii, which display morphological plasticity. They undergo a growth phase dependent transition from rod-shaped to plate-shaped cells $[15,16,18,19]$. In early-exponential phase 
$\left(\mathrm{OD}_{600}<0.1\right)$, cells are predominantly rod-shaped. They slowly transit to a mixed culture of rods and plates in mid-exponential phase $\left(\mathrm{OD}_{600} 0.1-0.6\right)$, and eventually have a homogenous plate-shaped morphology in late stationary phase $[16,19]$.

In addition to the growth phase, also the composition of the media significantly influences cell shape. Stable rod-formation is mainly observed in medium supplemented with casamino acids (essential amino acids and small peptides), optionally substituted with trace elements $[16,18,19]$. Maintenance of the rod-shaped morphology is dependent on CetZ in Hfx. volcanii, which is a tubulin like cytoskeleton protein [15]. On the other hand, stable plate shape formation partly relies on the peptide archaeaosortase (ArtA). ArtA is responsible for the lipid attachment of $H f x$. volcanii surface exposed proteins, including the S-layer, which is the main cell wall component of $H f x$. volcanii [20].

Interestingly, cell shape is linked with motility in $H f x$. volcanii $[15,21]$. Rod-shaped cells are very motile, while the plate-shaped cells are generally non-motile $[15,16]$. Only the rod-shaped $H f x$. volcanii cells display an archaellum, the archaeal motility structure, at their cell surface near the cell poles [16,22]. In contrast, the plate-shaped cells usually possess a remnant of the archaellum motor without the filaments [16]. In addition, chemosensory arrays that allow for directional movement, are absent from the plate-shaped cells in stationary phase [16,22]. An archaeal MinD homolog, named MinD4, seems to be involved in cellular positioning of archaella and chemosensory arrays in the rod-shaped cells of $H f x$. volcanii [18].

The accumulation of recent studies on the model $H f x$. volcanii has now allowed for the identification of several environmental and cellular factors contributing to the maintenance of its cell shape, which together provide a clear overview of the factors determining the morphological plasticity by growth phase dependent cell shape change. However, it is currently unclear if this phenomenon is a specific feature of Haloferax, or more common under other haloarchaea. Therefore, we have studied the cell morphologies of other members of the class Halobacteria Haloarcula hispanica and Haloarcula californiae. The genome of Haloarcula. hispanica (abbr. Har. hispanica) is available [23]. In contrast, Har. californiae (abbr. Har. californiae) was more recently isolated and its genome is not sequenced [24,25]. Both organisms are attractive models for studies on archaeal viruses, as they are hosts for many different archaeal viruses representing tailed, icosahedral, pleomorphic and spindle-shaped virus morphologies [26-32]. Har. hispanica was originally reported to form a heterogeneous population consisting of short, motile pleomorphic rods by a length of $0.5-1.0 \mu \mathrm{m}[25,33]$. On other occasions, a small proportion of Har. hispanica population was additionally observed as large, non-motile, coccoid cells of 2-3 $\mu \mathrm{m}$ in diameter and a low frequency of thick 'cluster' like cells [34]. The cell morphology of Har. californiae has not been studied previously.

In this study, we conducted a detailed analysis of the morphology of two Haloarcula species and show that both display morphological plasticity and undergo growth phase dependent cell shape change, albeit both in a different fashion. In addition, we find that there is likely a similar link between growth phase and motility, as has been observed in $H f x$. volcanii.

\section{Materials and Methods}

\subsection{Media and Growth Conditions}

Har. californiae ATCC 33799 [35] and Har. hispanica [33] cells were cultured aerobically at 37,42 , or $45^{\circ} \mathrm{C}$ under constant rotation at $120 \mathrm{rpm}$. They were grown in media prepared with $30 \%(w / v)$ salt water (SW) containing (per liter) $240 \mathrm{~g} \mathrm{NaCl}, 30 \mathrm{~g} \mathrm{MgSO}_{4} \cdot 7 \mathrm{H}_{2} \mathrm{O}, 35 \mathrm{~g}$ $\mathrm{MgCl}_{2} \cdot 6 \mathrm{H}_{2} \mathrm{O}, 7 \mathrm{~g} \mathrm{KCl}, 80 \mathrm{mM}$ Tris- $\mathrm{HCl}$ (pH 7.2) and $5 \mathrm{mM} \mathrm{CaCl}_{2}$ [36]. The $30 \%$ stock of SW was diluted to make the working media with either $18 \%(w / v)$ or $23 \%(w / v)$ SW. For growth in rich YPC (yeast, peptone, casamino acids) medium [37] SW was supplemented with $0.5 \%$ $(w / v)$ yeast extract (Difco, Thermo Fisher Scientific, Basingstoke, Hampshire, UK), 0.1\% $(w / v)$ peptone (Oxoid, Thermo Fisher Scientific, Basingstoke, Hampshire, UK), and 0.1\% $(w / v)$ casamino acids (Difco). For growth in rich modified growth medium (MGM) [38], 
$0.5 \%,(w / v)$ yeast extract and $0.1 \%(w / v)$ peptone were added. For growth in selective CA (casamino acids) medium [37], casamino acids were added to the SW to a final concentration of $0.5 \%(w / v)$. CA medium modified with trace element solution (CAB) [15] was prepared in the same manner as CA medium with addition of 1/100 expanded trace element solution.

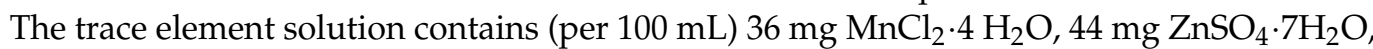
$230 \mathrm{mg} \mathrm{FeSO} 4 \cdot 7 \mathrm{H}_{2} \mathrm{O}, 5 \mathrm{mg} \mathrm{CuSO} 4 \cdot 5 \mathrm{H}_{2} \mathrm{O}$ (filter sterilized). The medium was set to $\mathrm{pH}$ 7.2 adjusted with $\mathrm{KOH}$. Growth in different media and temperatures was monitored for 7 days. The experiments were performed in triplicates (containing 3 biological replicates) for each medium, temperature, and salt condition.

\subsection{Motility Assay on Semi-Solid Agar Plates}

Motility assays were performed as described previously [16,21]. Semi-solid agar plates were prepared with YPC, MGM, CA, or CAB medium made of either 18 or $23 \%$ SW containing $0.3 \%(w / v)$ agar. Cell cultures were grown to an $\mathrm{OD}_{600}$ of 0.5 and about $10 \mu \mathrm{L}$ of culture was spotted on a semi-solid agar plate for inoculation. The experiments were performed in at least triplicates (containing at least 2 biological replicates) per plate. The motility ring formed after cultivation of plates at $45^{\circ} \mathrm{C}$ for 6 days was analyzed by scanning of plates and measurement of the diameter using Fiji/ImageJ [39]. To analyze statistically significant differences of motility rings formed on media prepared with different salinities a nonparametric Mann-Whitney-Wilcoxon test was performed.

\subsection{Phase-Contrast Light Microscopy}

Phase-contrast images for cell shape analysis were recorded for Har. californiae and Har. hispanica grown in CA medium containing 23\% SW. For microscopy, cultures from different growth phases were diluted to an $\mathrm{OD}_{600}$ of 0.1 and $5 \mu \mathrm{L}$ cell suspension was placed at the centre of an agarose pad $(0.4 \%(w / v)$ agar, $18 \% \mathrm{SW})$ prepared on a glass slide. A coverslip was placed on top. Images were acquired at 100x magnification in the oil immersion Phase contrast mode (PH3) using an Axio Observer.Z1 inverted microscope (Carl Zeiss, Oberkochen, Germany) and processed to analyze cell shapes using the plugin MicrobeJ of Fiji/ImageJ.

Samples taken from motility rings were incubated for $1 \mathrm{~h}$ at $45^{\circ} \mathrm{C}$ in the respective liquid media. Agar was removed by centrifugation at $2000 \mathrm{~g}$. The cells in the supernatant were observed with phase-contrast microscopy to analyze the cell shape and swimming behaviour on agar pads or in microscopy dishes, respectively. For imaging of motile cells, $1.5 \mathrm{~mL}$ of growing culture diluted to an $\mathrm{OD}_{600}$ of 0.1 was pipetted in a round $\mathrm{DF}$ 0.17-mm microscopy dish (Bioptechs, PA, USA) and observed at $100 \times$ magnification in the phase contrast mode. Time-lapse imaging was performed at $45{ }^{\circ} \mathrm{C}$ with an Axio Observer.Z1 inverted microscope (Zeiss) equipped with a heated XL-5 2000 Incubator running VisiVIEW software.

\subsection{Automated Image Analysis of Cell Shapes}

Phase-contrast images were analyzed using Fiji/MicrobeJ $[40,41]$. The circularity of free cells was determined by automated calculation. The minimum cell size was $0.3 \mu \mathrm{m}^{2}$ (1 pixel $=0.065 \mu \mathrm{m})$. Fragmented cells, cells that contained holes, or cells that merged together in bigger aggregates were excluded from analysis. Cell circularities and diameters were calculated individually for all examined optical densities and binned into ranges of $0.001-0.100,0.101-0.200,0.201-0.600,0.601-1.000$, and 1.001-1.900 for further processing and analysis. An unpaired t-test was performed to test for statistically significant differences in cell diameters. Cell circularities are shown as frequency distributions grouped in bins of 7 intervals from 0.4 to 1 . A nonparametric Mann-Whitney-Wilcoxon test was performed to analyze significant differences in cell circularities at certain optical densities. 


\subsection{Transmission Electron Microscopy}

Har. californiae and Har. hispanica cells were grown at $37^{\circ} \mathrm{C}$ in CA medium prepared with $18 \%$ SW buffered with 10 mM HEPES (4-(2-hydroxyethyl)-1-piperazineethanesulfonic acid) ( $\mathrm{pH}$ 7.0). Cells from early-exponential phase cells were concentrated 10-20-fold by centrifugation and resuspension in CA medium before being adsorbed to glow-discharged carbon-coated copper grids (Plano $\mathrm{GmbH}$, Wetzlar, Germany) with Formvar films. The samples were washed three times in drops of sterile $2 \mathrm{M} \mathrm{NaCl}$ and subsequently stained for $15 \mathrm{~s}$ with sterile filtered $2 \%(w / v)$ uranyl acetate prepared in $2 \mathrm{M} \mathrm{NaCl}$. Grids were examined using a Hitachi 7800 transmission electron microscope coupled to an EMSIS Xarosa (EMSIS GmbH, Muenster, Germany) camera or an Zeiss Leo 912 Omega with Dual Speed 2K-On-Axis charged-coupled device (CCD) camera TRS, Sharp-Eye (TRS Systems, Moorenweis, Germany).

\section{Results}

\subsection{Haloarcula sp. undergo a Cell Shape Transition during Growth}

We analyzed the effect of different growth conditions on the doubling times of Har. californiae and Har. hispanica. To establish optimal cultivation conditions of both strains, common halophilic growth media with different compositions were tested (Figures S1 and S2). Both strains grew actively under aerobic conditions and had comparable doubling times. Within the tested temperatures $\left(37,42\right.$, and $\left.45^{\circ} \mathrm{C}\right)$, the shortest doubling times were achieved when cells were grown at $42{ }^{\circ} \mathrm{C}$. The salinity of the medium had no significant effect on the doubling times of both strains (Figures S1 and S2). The shortest doubling times were $5.5 \mathrm{~h}$ and $6 \mathrm{~h}$ for Har. hispanica and Har. californiae, respectively, when strains were grown in $\mathrm{CAB}$ media at $42^{\circ} \mathrm{C}$.

When grown at $37^{\circ} \mathrm{C}$, both strains exhibited prolonged lag-phases. However, as soon as the strains started their logarithmic growth phase, doubling times were relatively comparable with the higher temperatures: doubling times of $7 \mathrm{~h}$ (Har. hispanica) and $6 \mathrm{~h}$ (Har. californiae) in CAB media and $10 \mathrm{~h}$ (Har. hispanica) and $9.5 \mathrm{~h}$ (Har. californiae) in YPC medium. We did observe that colonies of both strains grew faster on solid medium prepared with $23 \% \mathrm{SW}$, than with $18 \% \mathrm{SW}$. This corresponds with the reported optimal salinities for Har. hispanica and Har. californiae growth [25,33].

As Haloferax cells have been shown to undergo a growth phase dependent shape change in CA medium [16,19], we also studied the cell shape of Har. californiae and Har. hispanica cells growing in CA (prepared with $23 \%$ SW) by phase contrast microscopy (Figure 1). We distinguish four growth phases: very early (I, OD 600 0.01-0.1), early (II, $\mathrm{OD}_{600}$ $0.1-0.2)$, mid (III, $\mathrm{OD}_{600} 0.2-0.1$ ) exponential phase and late stationary phase (IV, $\mathrm{OD}_{600} 1.0-$ 2.0). Har. hispanica cells were mainly observed as rod-shaped during most growth phases. In addition, some very short rods and round cells were also found during all growth phases. Only, in late stationary phase, some of the cells appeared slightly triangular (Figure 1c). This observation of cell shape is reflected by the relative cell circularity distributions of Har. hispanica cells from different optical densities (Figure 1c). Round cells typically have a circularity value of $0.9-1$. During most growth phases, there is a significant population of Har. hispanica with a circularity $<0.9$. We detected a significant difference between each of the bins for each strain $(p<0.0001)$, apart from the two highest OD bins for Har. hispanica (0.6-1.0 vs. 1.0-1.9) and the $0.1-0.2$ vs. $1.0-1.9$ bin for Har. californiae. In early and mid-exponential growth phases, $\sim 2 \%$ of Har. hispanica cells were extraordinarily large $\left(\sim 4-5 \mu \mathrm{m}^{2}\right)$ and pleomorphic in shape (Supplementary Figure S5a). Whereas the shape remained rod-shaped through most of the growth phases, the size of cells changed significantly. The average length of cells from early exponential was $\sim 1.9 \mu \mathrm{m}$ and this was slowly decreasing to $\sim 1.4 \mu \mathrm{m}$ in mid-exponential and $1.6 \mu \mathrm{m}$ in late stationary growth phases (Figure 1c). The progressive reduction in the size of the cells is statistically significant between all bins $(p<0.0001)$. Thus, Har. hispanica also shows a growth phase dependent cell shape change, like $H f x$. volcanii. However, it remains rod-shaped during almost all 
growth phases, and only transitions to slightly pleomorphic and triangular cells at very late stationary phase.

(a)

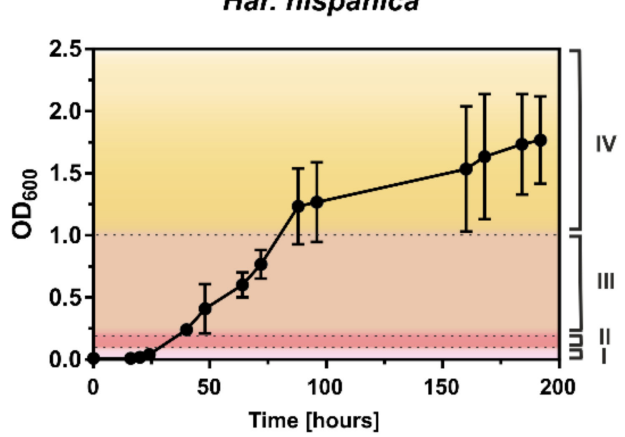

(c)

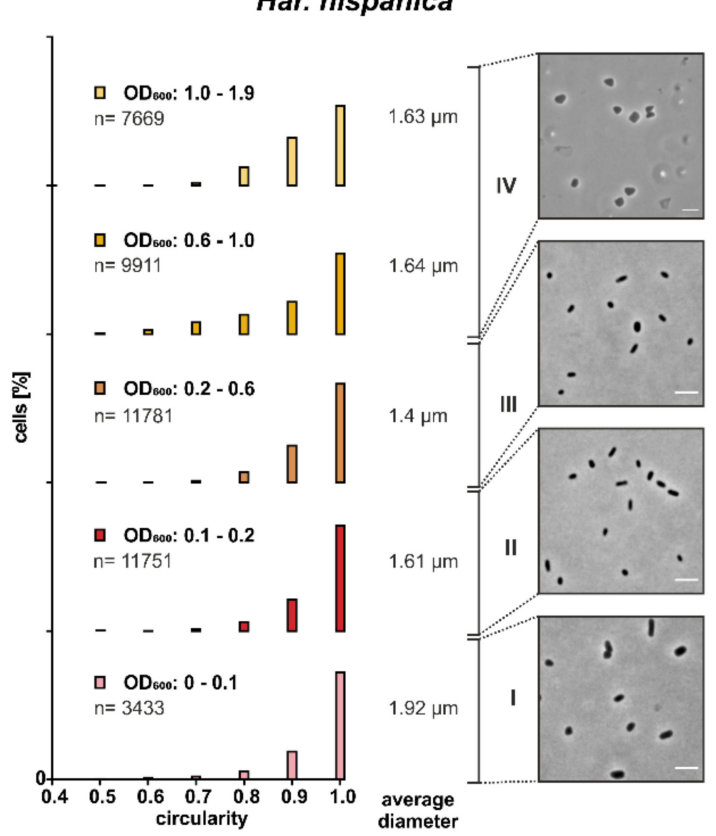

(b)

Har. californiae

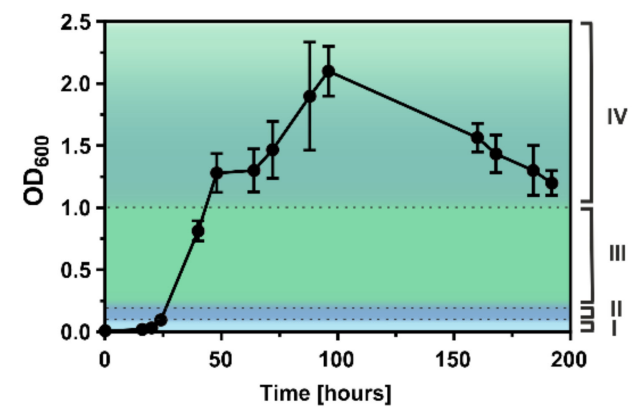

(d)

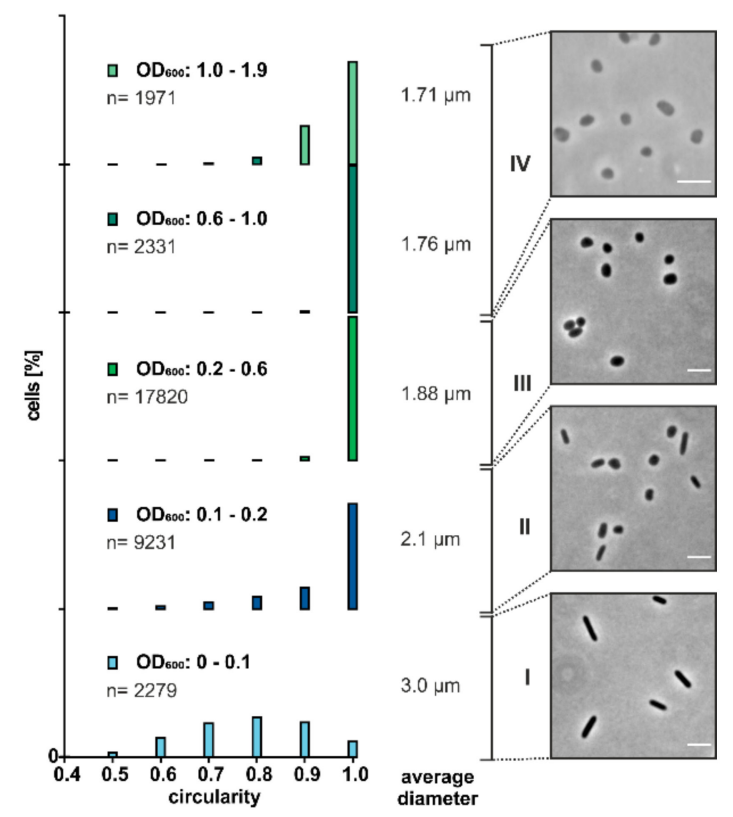

Figure 1. Correlation between growth phase and cell shape in Haloarcula sp. Representative growth curves of at least 3 independent biological replicates of (a) Har. hispanica and (b) Har. californiae grown in CA medium containing $23 \%(w / v)$ salinity at $42{ }^{\circ} \mathrm{C}$. Curves represent mean of three technical replicates. Error bars represent the standard deviation of three technical replicates. Dotted lines indicate time points of sampling for cell shape analysis. For more biological replicates, see Figures S1 and S2. (c,d) The cell shape of Haloarcula sp. was analyzed using light microscopy. Representative phase contrast images of Har. hispanica and Har. californiae are shown from very early (I, $\mathrm{OD}_{600} 0.01-0.1$ ), early (II, OD 600 0.1-0.2) mid (III, $\mathrm{OD}_{600}$ 0.2-0.1) and late (IV, $\mathrm{OD}_{600}$ 1.0-2.0) exponential growth phases. Scale bars represent $4 \mu \mathrm{m}$. (c,d) Relative frequency distributions of circularity measurements of (c) Har. hispanica cells and (d) Har. californiae cells from different optical densities (I-IV, see $\mathbf{a}$ and $\mathbf{b}$ ). $\mathrm{y}$-axis is percentage of cells. The sum of the bar heights per bin equals $100 \%$. Nearly perfect round cells are displayed by a circularity of 1 . Data binning was used to combine measurements from similar optical densities in intervals of $0.001-0.1,0.101-0.2,0.201-0.6,0.601-1.0,1.01-1.9$. These intervals correspond to the four recognized growth phases of both Haloarcula sp. (see text). The only exception is that the late stationary phase is divided in two bins to better reveal addition shape alteration in this growth phase. Above each circularity graph, the $\mathrm{OD}_{600}$ of the bins is shown, as well as the total number of analyzed cells (n). The 'average diameter' displays the average cell diameter of the population in each bin. 
During early exponential growth $\left(\mathrm{OD}_{600} \sim 0.01-0.1\right)$, Har. californiae cells were observed as long rods (Figure 1d). In correspondence with the observation by light microscopy, the measured cell circularity of the population also revealed the high abundance of elongated rod-shaped cells in early exponential growth phase (until $\mathrm{OD}_{600} 0.1$; Figure $1 \mathrm{~d}$ ). Only a few round cells (circularity 0.9-1) were observed within this population. Upon further growth, cells transitioned from rod-shaped to plate or round-shaped cells and formed a mixed population of the two cell shapes (Figure $1 \mathrm{~d})$. In mid-exponential phase $\left(\mathrm{OD}_{600}\right.$ $\sim 0.2-1$ ), cells became increasingly plate or round-shaped. Just like Har. hispanica, some cells of Har. californiae from late stationary phases, appeared slightly triangular, represented by a higher frequency of cells with a circularity below 0.9 (Figure 1d).

Measurements of the cell length within populations of cells are consistent with the described growth phase dependent cell shape change. In early exponential phase, Har. californiae cells had a length of $\sim 3 \mu \mathrm{m}$, and this decreased to $\sim 1.7 \mu \mathrm{m}$ in stationary phase (above $\left.\mathrm{OD}_{600} 1.0\right)$ (Figure 1d). The decrease in cell size was statistically significant between all bins $(p<0.0001)$ throughout almost all optical densities. An exception to this are bins of OD $0.6-1.0$ vs. $0.1-1.9$. Similarly to Har. hispanica, we observed $\sim 5 \%$ of large pleomorphic cells (diameter $\sim 5-6 \mu \mathrm{m}$ ) at early log phase (Supplementary Figure S5b). This population decreased to $0.01 \%$ in mid-exponential phase.

The cell shape transition of Har. californiae is very reminiscent to the reported cell shape transition of $H f x$. volcanii $[15,16,19]$ and $H f x$. gibbonsii [42], during growth in liquid medium. The exact ODs at which the transition from rod-shaped to plate-shaped cells occurs is species-dependent and different for all strains.

Comparison between the cell shape in CA medium prepared with 18 or 23\% SW showed no difference between the media with different salinities (data not shown). Thus, both Har. californiae and Har. hispanica undergo a growth phase dependent cell shape change, which results in plate-shaped and triangular-shaped cells in late stationary phase. However, both species differ in the morphology of cells in early and mid-exponential phase.

\subsection{Har. hispanica and Har. californiae Are Motile}

As the cell morphologies of Hfx. volcanii and Hfx. gibbonsii LR2-5 are linked with motility $[19,42]$, we studied if similar correlation can be found for Haloarcula species. Cells were grown in CA medium and observed at similar ODs as for cell-shape analysis with time lapse microscopy at $42{ }^{\circ} \mathrm{C}$. In case of Har. californiae, no motile cells were observed at any of the analyzed ODs (Video 1). For Har. hispanica, we observed motility between $\mathrm{OD}_{600}$ of 0.1 and 1.5 , where $\sim 40 \%$ of the population showed swimming motility (Video 2 ). To test if the observed absence of motility for Har. californiae, could be dependent on the growth medium, time lapse microscopy was also applied to cells grown in YPC, MGM, and CAB media prepared with different salinity (18 or $23 \% \mathrm{SW})$. In all cases, no motile cells were observed (data not shown).

After our analysis of motility in liquid medium of the two Haloarcula strains, we examined if archaella are produced in both strains. We harvested the cells at the midexponential growth phase $\left(\mathrm{OD}_{600} 0.1-0.2\right)$, where Har. hispanica is motile. Observation by transmission electron microscopy (TEM) showed that Har. hispanica cells usually contained one or two long archaella filaments at the cell poles (Figure 2a,b). In contrast, no cell appendages were observed on the surface of Har. californiae (Figure 2c,d).

To test whether the motility of Har. californiae and Har. hispanica could be triggered in another fashion, cells were spotted on semi-solid agar plates. On semi-solid agar plates, cells have the possibility to swim away from the centre of inoculation, due to local starvation, and form a motility ring. By this assay, not only the functioning of the motility structure, but also that of the chemotaxis system is tested [43]. Motility assays revealed expanding motility rings of Har. hispanica and Har. californiae after 6 days of incubation (Figure 3). Salinity of the tested medium had a profound impact on motility, and the motility rings were always significantly larger in medium prepared with $23 \% \mathrm{SW}$ for both Har. californiae and Har. hispanica than in lower salinity $(p<0.0001)$. Under higher salinity, 
the motility rings of Har. californiae and Har. hispanica had diameters of $\sim 5$ and $\sim 6 \mathrm{~cm}$, respectively. No motile cells of Har. hispanica were found when grown on YPC plates with $18 \%$ SW (Figure 3a). On CA, CAB, and MGM plates with $18 \%$ salinity, the motility rings of both strains were significantly reduced compared with those in similar medium with $23 \%$ SW. After 6 days, diameters were not more than $\sim 2-4 \mathrm{~cm}$ (Figure 3 and Figure S3).
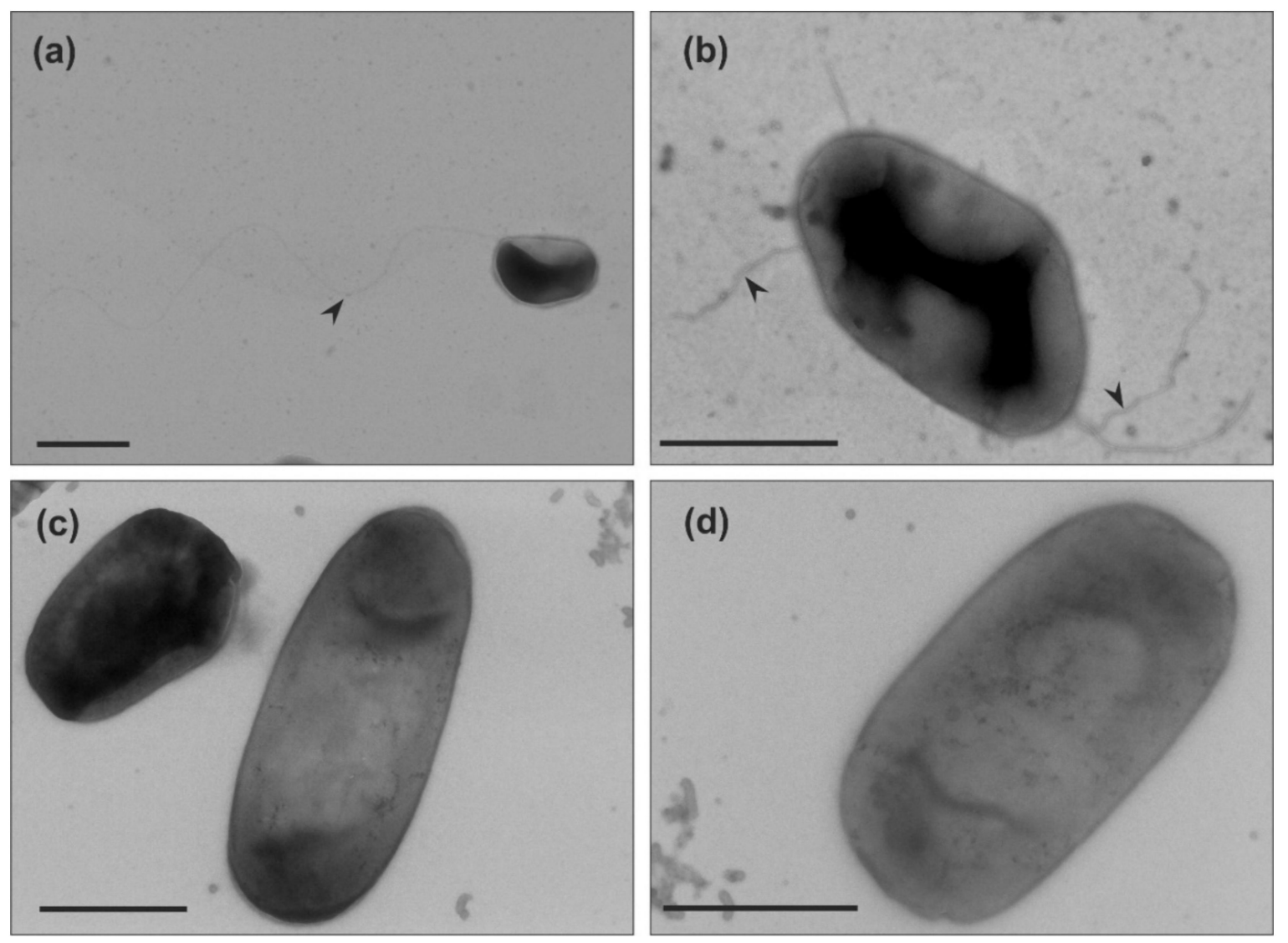

Figure 2. Transmission electron microscopy of (a,b) Haloarcula hispanica and (c,d) Haloarcula californiae morphology types from early-exponential growth phases $\left(\mathrm{OD}_{600}\right.$ 0.1-0.2). Black arrow heads indicate the archaellum. Cells were negatively stained with $2 \%$ uranyl acetate. Scale bar, $1 \mu \mathrm{m}$.

When the two strains were spotted on the same plate, exclusion zones between flanking motility rings were observed, suggesting that the cells can sense the presence of the other strain and stop motility in that direction (Figure S4a). This was also the case for motility rings produced by the same strain (Figure S4b). Similar findings were reported for $H f x$. volcanii, where these exclusion zones also appear between motility rings of the same strain [15]. However, a mechanism by which cells could sense the leading edge of another motility ring, has so far not been discovered [15].

The above-described results indicate that both Haloarcula strains possess a functional chemotaxis system and motility structure. However, during growth in liquid medium, this motility seems not induced for Har. californiae. The absence of archaella at the surface of Har. californiae cells grown in liquid medium, suggests that the lack of motility observed under these conditions, is the result of downregulation of the archaellum filament production. Local starvation on the semi-solid agar plates might induce archaellum production and hence motility.

\subsection{Cell Shape is Coupled With Motility on Semi-Solid Agar Plate}

After we observed that both Har. californiae and Har. hispanica formed motility rings on semi-solid agar plate, we analyzed the cell shape and motility of cells on semi-solid agar 
plates, to test for link between motility and cell shape. The motility rings were divided in three different zones, and with a pipet tip, cells were extracted from each zone. The cell shape and motility behavior of cells from each zone were observed by phase contrast microscopy. Cells obtained from semi-solid agar plates were predominantly rod-shaped and motile (Figure 4). Time-laps imaging revealed that upon resuspension in fresh liquid media and incubation at $45^{\circ} \mathrm{C}$, cells were actively swimming (Video 3,4). In all analyzed samples originating from motility rings, a mixture of motile rod-shaped cells and plateshaped cells was observed (Figure 4). The majority of cells was rod-shaped and this cell morphology of the population was independent of the position on the motility ring from which cells originated.

(a)

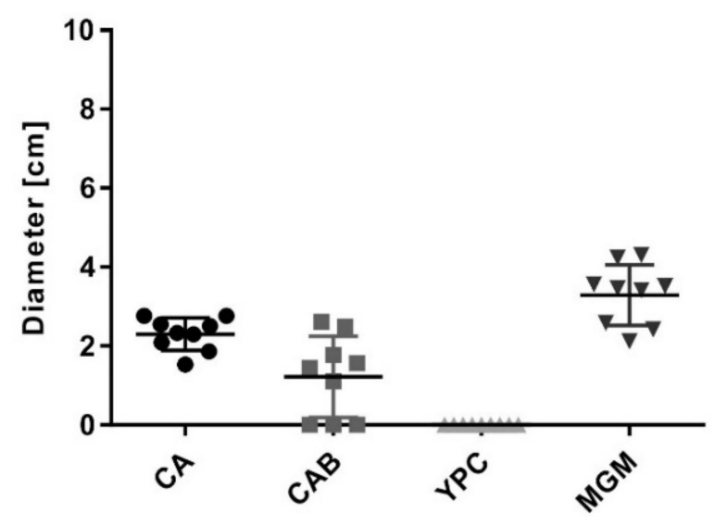

(c)

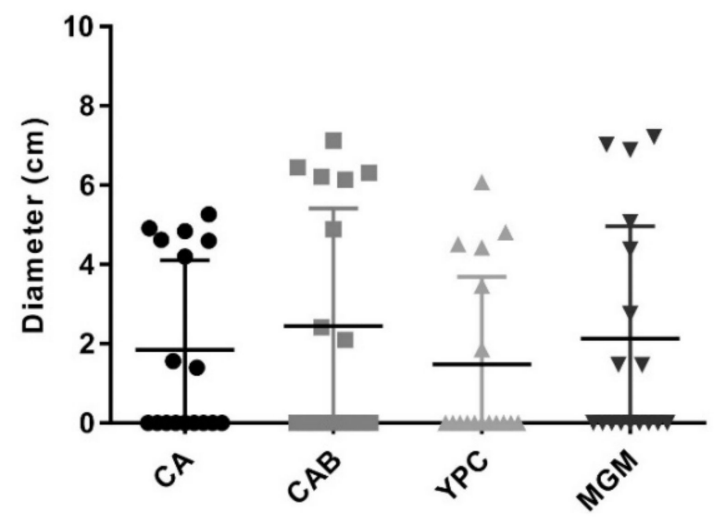

(b)

\section{$23 \%$ salt}

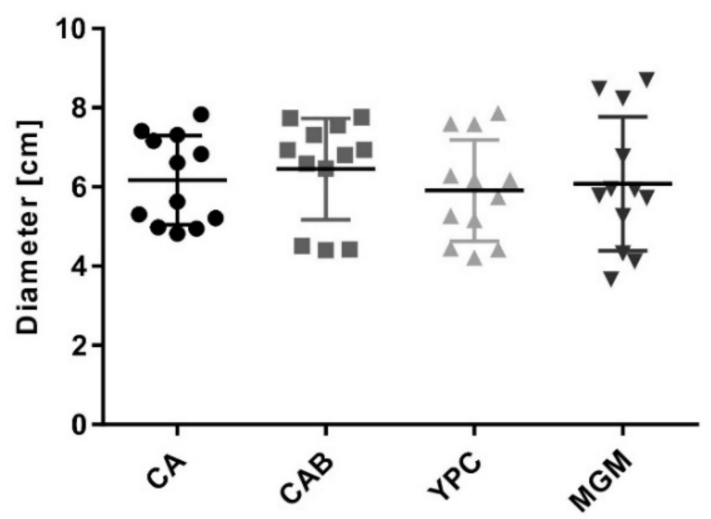

(d)

$23 \%$ salt

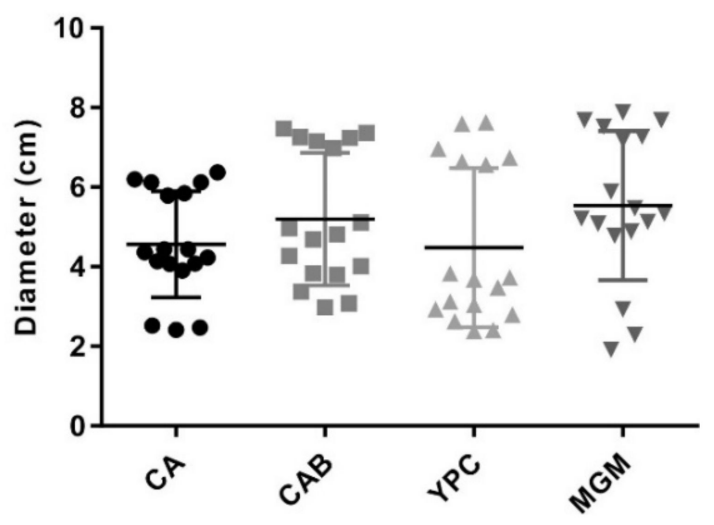

Figure 3. Motility of Haloarcula sp. on semi-solid agar plates. Quantification of the motility ring diameters formed by $(\mathbf{a}, \mathbf{b})$ Har. hispanica and (c,d) Har. californiae on semi-solid agar plates with different media in (a,c) $18 \%$ or (b,d) $23 \%$ SW. Calculations were made using more than three independent experiments including at least two biological replicates each. The middle black line indicates mean, lower and upper lines the standard deviation.

Time lapse imaging of cells from the different zones in the motility ring showed different fractions of motile cells dependent on the sampling site (Figure 4). Whereas $\sim 70 \%$ of Har. hispanica cells at the leading edge of the motility ring (Position 1) showed swimming behaviour, only $\sim 50 \%$ were found to be actively swimming at the centre of the ring (Position 3). The amount of Har. californiae cells that were observed swimming when removed from motility plates, was lower compared to Har. hispanica. Only 60\% of Har californiae cells from Position 1 were actively swimming. This number decreased to $\sim 10 \%$ when sampling at the centre of the motility ring (Position 3). 
(a)

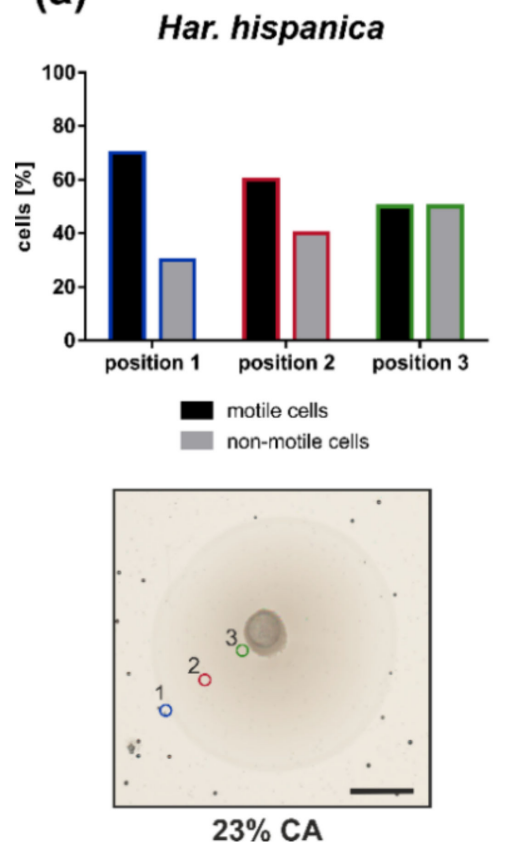

(b)

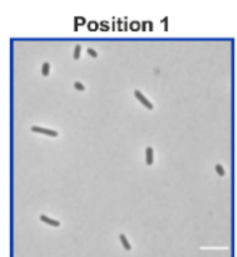

Position 2

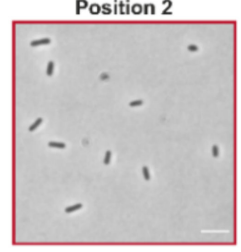

Position 3

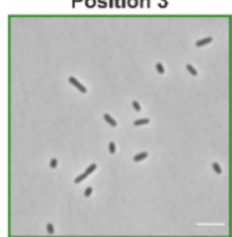

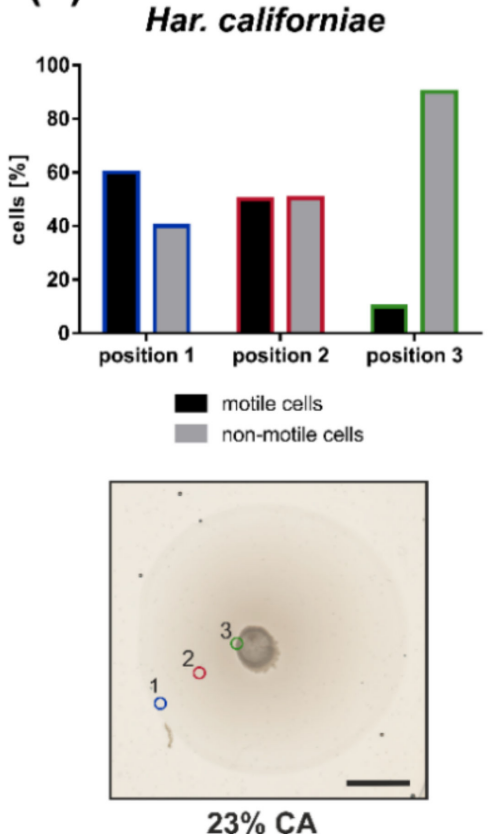

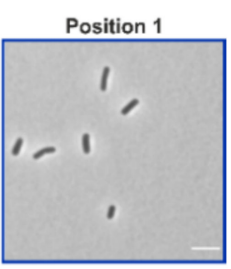

Position 2

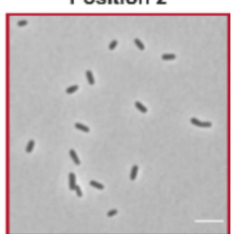

Position 3

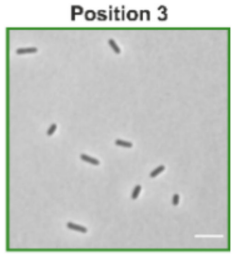

Figure 4. Cell shape and swimming behavior on semi-solid agar plates. Motility ring formation of (a) Har. hispanica and (b) Har. californiae. Photo in the lower left corner shows a typical motility ring on semi-solid agar plate, which indicated sampling positions 1-3 for cell shape analysis. Scale bars represent $1 \mathrm{~cm}$. Images on the right, represent phase contrast light microscopy images of representative cell shapes at indicated sampling positions (colors from sampling positions correspond with coloring of the image frame). Scale bars represent $4 \mu \mathrm{m}$. Graph in the top left corner indicates the $\%$ of cells from the total population that is motile (black) or not motile (gray). Colors correspond with sampling positions from semi-solid agar plates.

TEM of negatively stained cells from the leading edge of the motility ring showed that Har. hispanica and Har. californiae displayed filamentous structures at its surface (Figure 5). The majority were filaments of $\sim 20 \mathrm{~nm}$ in diameter and 5-8 $\mu \mathrm{m}$ in length, that had a wavy appearance and often formed tufts. Therefore, they likely present archaella. The appearance of Har. hispanica was similar as those cells from liquid medium in mid-exponential phase (Figure 2a,b). In addition, on the surface of Har. californiae cells shorter thinner filaments $(\sim 11 \mathrm{~nm})$ were occasionally observed as well, which we assume represent adhesive pili, as their diameter corresponds with such pili from $H f x$. volcanii [44,45]. Archaella were observed both on rod-shaped and on round cells, although it is not sure that these observed cell shapes by TEM represent the natural cell morphology, as cells were not fixed during preparation. 

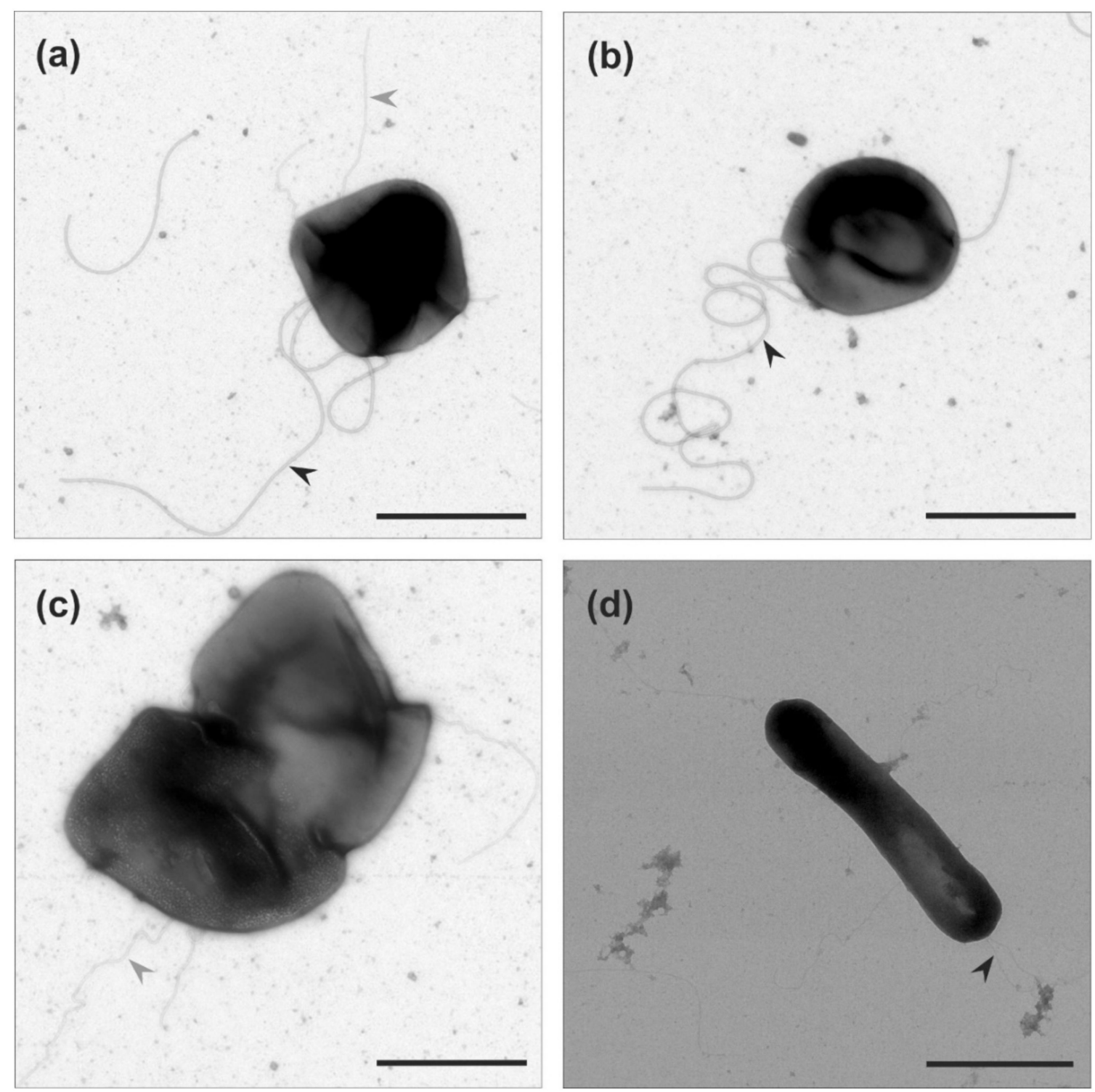

Figure 5. Transmission electron microscopy of (a-c) Haloarcula californiae cells with distinguishable archaella and pili and (d) Haloarcula hispanica rod-shaped morphology types from semi-solid agar plates. Black arrow heads indicate archaella. Grey arrow heads indicate pili. Scale bars represent $1 \mu \mathrm{m}$.

\section{Discussion}

Most haloarchaea have initially been reported to display pleomorphic cell shapes. Recently, it was discovered that the cell shape of the model haloarchaeon Hfx. volcanii is dependent on the growth phase and it thus displays morphological plasticity $[16,19]$. Cells transit from rod-shaped to plate-shaped morphology in the course of early-exponential to stationary growth phases $[16,19]$. Moreover, cells shape was found to be linked with motility, and particularly the rod-shaped $H f x$. volcanii cells are motile $[15,16]$. We now addressed the question if this growth phase dependent cell shape change is a specific characteristic of Hfx. volcanii, or if it is more common for haloarchaea. We studied the cell shape and motility behavior in detail during growth of two Haloarcula strains: Har. hispanica and Har. californiae.

Our results show that both strains undergo growth phase dependent cell shape alteration (Figure 1). In case of Har. californiae and Har. hispanica, the behavior is similar to that of that of Hfx. volcanii and Hfx. gibbonsii LR2-5 [15,16,19,42] as also a transition from rodto plate-shaped cells was observed, although the transition took place later during growth 
for Har. hispanica compared to Hfx. volcanii and Har. californiae (Figure 1a,b). We observed three main differences between the Haloarcula and Haloferax species. (i) The presence of a small but constant population of extremely large pleomorphic cells in the early- and mid-exponential growth phase of Har. hispanica, which is not observed for Haloferax. Har. californiae cultures from early exponential phase also display a low fraction of extremely large cells, but these large cells disappear later during growth. Har. hispanica was originally described as containing $0.01-0.1 \%$ of large cells that are 'cluster-shaped' [26,34]. Such cells have been never observed for wild type $H f x$. volcanii and their appearance is a bit like FtsZ knock-outs of $H f x$. volcanii [46]. The morphology of these 'cluster cells' described previously for Har. hispanica, is similar to those that we observed for both strains in early and mid-exponential phase, as they contained 'phase bright capsules', and formed smaller clusters of divided cells (Figure S5). (ii) The second difference is that Haloarcula cells not only change their cell shape, but also generally become smaller. For both species, the average cell diameter is decreasing throughout development and cells become smaller towards late exponential and stationary phase. (iii) And finally, the Haloarcula strains generally contained a mixture of plate and triangular shaped cells in stationary phase, whereas Haloferax cells are mainly reported plate shaped in this phase, although triangular cells were also reported for $H f x$. volcanii [11,19,42].

Interestingly, in Haloarcula species, the cell shape also seems to be linked with motility, as is the case for Haloferax $[15,16,21]$. Cells from motility plate are majorly rod-shaped. (Figure 4). However, the rod-shape on its own is not sufficient for motility, since we primarily observed non-motile rod-shaped Har. californiae cells in liquid medium in earlyexponential phase. The reason for non-motile phenotypes of Har. californiae in liquid medium, is the lack of archaella in Har. californiae (Figure 2). This discrepancy between motility behavior in liquid medium vs. on semi-solid agar plates (Figure 5), can be explained by local starvation at the site of inoculation on the semi-solid agar plate, which functions as a trigger for the chemotaxis system, but might also indirectly induce archaellum production.

The observation that Haloarcula species, just like Haloferax species, undergo a shape change throughout growth, raise the question what the advantage of this morphological plasticity is. The link with motility might offer the most plausible explanation, as rodshaped cells are likely more aerodynamic as plate-shaped cells. The early-exponential phase, where the cell density is low, might reflects environmental conditions where motility is advantageous for cells to move towards habitats with optimal growth conditions. The stationary growth phase with high cell densities resembles conditions immediately prior to biofilm formation, where motility and the coupled rod-shape appearance are no longer advantages. However, there are several other advantages that have been proposed for rod-shaped morphology in general; such as (i) improved fluid shear stress, which might be advantageous in environments with strong currents, or (ii) symmetry, which contributes to equal division over daughter cells $[5,47,48]$. The smaller cells size that was observed in densely growing cultures, might be advantageous because total surface area is increased and could be the result of selection due to nutrient limitation.

\section{Conclusions}

The major findings of this work are summarized in Figure 6. These findings demonstrates that a growth phase dependent cell-shape change might be common amongst haloarchaea. Therefore, it underscores the importance of future studies on motility and cell-shape in haloarchaea to identify the main protein players, and the regulatory network in which they are connected. In addition, studies on other Euryarchaea, might answer the question if this trait is exclusive for haloarchaea, or more widespread. 


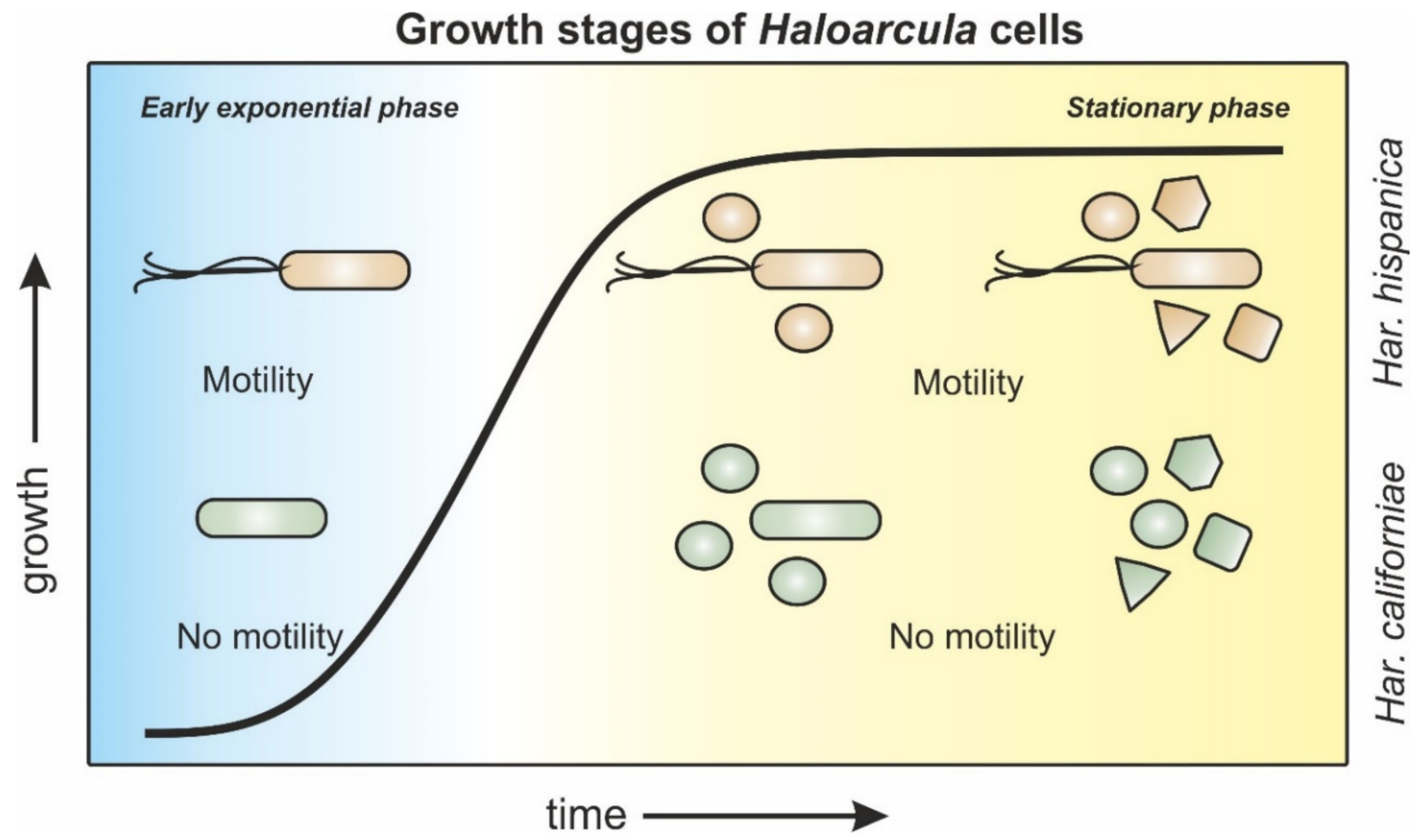

Figure 6. Schematic representation of morphology and motility behavior of Haloarcula sp. during different growth stages. Har. hispanica cells (orange) progress from rod-shaped, via a mixed population of rod- and round-shaped cells towards a late-stationary population with mixed cell shapes of rod-, round-, triangle-, and square-shaped cells. Rods are motile throughout all growth phases. Har. californiae cells (green) transition from rod-shaped cells in early exponential growth phases towards a mixed population of rod and round cells in mid-exponential phases. Cells from late exponential and stationary growth phases display rod-, round-, triangle-, and square-shapes. Cells are non-motile throughout all stages of growth.

Supplementary Materials: The following are available online at https:/ /www.mdpi.com/2076-2 607/9/2/231/s1, Figure S1. Growth analysis of Haloarcula californiae in different media and temperatures, Figure S2. Growth analysis of Haloarcula hispanica in different media and temperatures, Figure S3. Motility rings on semi-solid agar plates, Figure S4. Exclusion zones of motility structures of Haloarcula hispanica and Haloarcula californiae, Figure S5. Cell shapes of Haloarcula sp. deviating from the norm, Video S1: Time-laps imaging of non-motile cells of Haloarcula californiae, Video S2: Time-laps imaging of motile cells of Haloarcula hispanica, Video S3: Time-laps imaging of motile cells of Haloarcula hispanica from semi-solid agar plates, Video S4: Time-laps imaging of motile cells of Haloarcula californiae from semi-solid agar plates.

Author Contributions: T.E.F.Q., H.M.O., and S.S. designed experiments. S.S. and M.R.-F. performed experiments. All authors have read and agreed to the published version of the manuscript.

Funding: This work was supported by the Deutsche Forschungsgemeinschaft (German Research Foundation) with an Emmy Nöther grant (411069969) and by the University of Helsinki and Academy of Finland funding for FINStruct and Instruct Centre FI, part of Biocenter Finland and Instruct-ERIC (European Research Infrastructure Consortium), respectively.

Institutional Review Board Statement: "Not applicable" for studies not involving humans or animals. Informed Consent Statement: "Not applicable" for studies not involving humans.

Data Availability Statement: The data presented in this study are available in https://www.mdpi. com/2076-2607/9/2/231.

Acknowledgments: We thank Marina Geiger and Drishya S. Gopan for the support with experiments. The TEM (funded by the DFG grant INST 39/1153-1) is operated by the University of Freiburg, Faculty of Biology, as a partner unit within the Microscopy and Image Analysis Platform (MIAP), Freiburg. 
Conflicts of Interest: The authors declare no conflict of interest.

\section{References}

1. Van Teeseling, M.C.F.; De Pedro, M.A.; Cava, F. Determinants of Bacterial Morphology: From Fundamentals to Possibilities for Antimicrobial Targeting. Front. Microbiol. 2017, 8, 1264. [CrossRef] [PubMed]

2. Margolin, W. Sculpting the Bacterial Cell. Curr. Biol. 2009, 19, R812-R822. [CrossRef]

3. Randich, A.M.; Brun, Y.V. Molecular mechanisms for the evolution of bacterial morphologies and growth modes. Front. Microbiol. 2015, 6, 580. [CrossRef] [PubMed]

4. Typas, A.; Banzhaf, M.; Gross, C.A.; Vollmer, W. From the regulation of peptidoglycan synthesis to bacterial growth and morphology. Nat. Rev. Microbiol. 2011, 10, 123-136. [CrossRef] [PubMed]

5. Kysela, D.T.; Randich, A.M.; Caccamo, P.D.; Brun, Y.V. Diversity Takes Shape: Understanding the Mechanistic and Adaptive Basis of Bacterial Morphology. PLoS Biol. 2016, 14. [CrossRef] [PubMed]

6. Andersen, L.P.; Rasmussen, L. Helicobacter pylori-coccoid forms and biofilm formation. FEMS Immunol. Med. Microbiol. 2009, 56, 112-115. [CrossRef]

7. Joshi, H.M.; Toleti, R.S. Nutrition induced pleomorphism and budding mode of reproduction in Deinococcus radiodurans. BMC Res. Notes 2009, 2, 123. [CrossRef]

8. Meriläinen, L.; Brander, H.; Herranen, A.; Schwarzbach, A.; Gilbert, L. Pleomorphic forms of Borrelia burgdorferi induce distinct immune responses. Microbes Infect. 2016, 18, 484-495. [CrossRef]

9. Robertson, P.; Abdelhady, H.; Garduño, R.A. The many forms of a pleomorphic bacterial pathogen-the developmental network of Legionella pneumophila. Front. Microbiol. 2014, 5. [CrossRef]

10. Hamamoto, T.; Takashina, T.; Grant, W.D.; Horikoshi, K. Asymmetric cell division of a triangular halophilic archaebacterium. FEMS Microbiol. Lett. 1988, 56, 221-224. [CrossRef]

11. Walsh, J.C.; Angstmann, C.N.; Bisson-Filho, A.W.; Garner, E.C.; Duggin, I.G.; Curmi, P.M.G. Division plane placement in pleomorphic archaea is dynamically coupled to cell shape. Mol. Microbiol. 2019, 112, 785-799. [CrossRef] [PubMed]

12. Mullakhanbhai, M.F.; Larsen, H. Halobacterium volcanii spec. nov., a Dead Sea halobacterium with a moderate salt requirement. Arch. Microbiol. 1975, 104, 207-214. [CrossRef] [PubMed]

13. Burns, D.G.; Camakaris, H.M.; Janssen, P.H.; Dyall-Smith, M.L. Cultivation of Walsby's square haloarchaeon. FEMS Microbiol. Lett. 2004, 238, 469-473. [CrossRef] [PubMed]

14. Walsby, A.E. A square bacterium. Nature 1980, 283, 69-71. [CrossRef]

15. Duggin, I.G.; Aylett, C.H.S.; Walsh, J.C.; Michie, K.A.; Wang, Q.; Turnbull, L.; Dawson, E.M.; Harry, E.J.; Whitchurch, C.B.; Amos, L.A.; et al. CetZ tubulin-like proteins control archaeal cell shape. Nature 2015, 519, 362-365. [CrossRef]

16. Li, Z.; Kinosita, Y.; Rodriguez-Franco, M.; Nußbaum, P.; Braun, F.; Delpech, F.; Quax, T.E.F.; Albers, S.V. Positioning of the motility machinery in halophilic archaea. mBio 2019, 10, e00377-19. [CrossRef]

17. Bisson-Filho, A.W.; Zheng, J.; Garner, E. Archaeal imaging: Leading the hunt for new discoveries. Mol. Biol. Cell 2018, 29, 1675-1681. [CrossRef]

18. Nußbaum, P.; Ithurbide, S.; Walsh, J.C.; Patro, M.; Delpech, F.; Rodriguez-Franco, M.; Curmi, P.M.G.; Duggin, I.G.; Quax, T.E.F.; Albers, S.-V. An Oscillating MinD Protein Determines the Cellular Positioning of the Motility Machinery in Archaea. Curr. Biol. 2020, 30, 4956-4972. [CrossRef]

19. De Silva, R.; Abdul-Halim, M.; Pittrich, D.; Brown, H.; Pohlschroder, M.; Duggin, I. Improved growth and morphological plasticity of Haloferax volcanii. bioRxiv 2020. [CrossRef]

20. Abdul-Halim, M.F.; Schulze, S.; DiLucido, A.; Pfeiffer, F.; Filho, A.W.B.; Pohlschroder, M. Lipid anchoring of archaeosortase substrates and midcell growth in haloarchaea. mBio 2020, 11, e00349-20. [CrossRef]

21. Quax, T.E.F.; Altegoer, F.; Rossi, F.; Li, Z.; Rodriguez-Franco, M.; Kraus, F.; Bange, G.; Albers, S.V. Structure and function of the archaeal response regulator CheY. Proc. Natl. Acad. Sci. USA 2018, 115, E1259-E1268. [CrossRef] [PubMed]

22. Li, Z.; Rodriguez-Franco, M.; Albers, S.V.; Quax, T.E.F. The switch complex ArlCDE connects the chemotaxis system and the archaellum. Mol. Microbiol. 2020, 114, 468-479. [CrossRef] [PubMed]

23. Liu, H.; Wu, Z.; Li, M.; Zhang, F.; Zheng, H.; Han, J.; Liu, J.; Zhou, J.; Wang, S.; Xiang, H. Complete genome sequence of haloarcula hispanica, a model haloarchaeon for studying genetics, metabolism, and virus-host interaction. J. Bacteriol. 2011, 193, 6086-6087. [CrossRef] [PubMed]

24. Javor, B.; Requadt, C.; Stoeckenius, W. Box-shaped halophilic bacteria. J. Bacteriol. 1982, 151, 1532-1542. [CrossRef]

25. Torreblanca, M.; Rodriguez-Valera, F.; Juez, G.; Ventosa, A.; Kamekura, M.; Kates, M. Classification of Non-alkaliphilic Halobacteria Based on Numerical Taxonomy and Polar Lipid Composition, and Description of Haloarcula gen. nov. and Haloferax gen. nov. Syst. Appl. Microbiol. 1986, 8, 89-99. [CrossRef]

26. Porter, K.; Kukkaro, P.; Bamford, J.K.H.; Bath, C.; Kivelä, H.M.; Dyall-Smith, M.L.; Bamford, D.H. SH1: A novel, spherical halovirus isolated from an Australian hypersaline lake. Virology 2005, 335, 22-33. [CrossRef]

27. Atanasova, N.S.; Roine, E.; Oren, A.; Bamford, D.H.; Oksanen, H.M. Global network of specific virus-host interactions in hypersaline environments. Environ. Microbiol. 2011, 14, 426-440. [CrossRef]

28. Demina, T.A.; Atanasova, N.S.; Pietilä, M.K.; Oksanen, H.M.; Bamford, D.H. Vesicle-like virion of Haloarcula hispanica pleomorphic virus 3 preserves high infectivity in saturated salt. Virology 2016, 499, 40-51. [CrossRef] 
29. Atanasova, N.; Heiniö, C.; Demina, T.; Bamford, D.; Oksanen, H. The Unexplored Diversity of Pleolipoviruses: The Surprising Case of Two Viruses with Identical Major Structural Modules. Genes 2018, 9, 131. [CrossRef]

30. Pietilä, M.K.; Atanasova, N.S.; Oksanen, H.M.; Bamford, D.H. Modified coat protein forms the flexible spindle-shaped virion of haloarchaeal virus His1. Environ. Microbiol. 2013, 15, 1674-1686. [CrossRef]

31. Bath, C.; Dyall-Smith, M.L. His1, an Archaeal Virus of the Fuselloviridae Family That Infects Haloarcula hispanica. J. Virol. 1998, 72, 9392-9395. [CrossRef] [PubMed]

32. Santos-Pérez, I.; Charro, D.; Gil-Carton, D.; Azkargorta, M.; Elortza, F.; Bamford, D.H.; Oksanen, H.M.; Abrescia, N.G.A. Structural basis for assembly of vertical single $\beta$-barrel viruses. Nat. Commun. 2019, 10, 1-9. [CrossRef] [PubMed]

33. Juez, G.; Rodriguez-Valera, F.; Ventosa, A.; Kushner, D.J. Haloarcula hispanica spec. nov. and Haloferax gibbonsii spec, nov., Two New Species of Extremely Halophilic Archaebacteria. Syst. Appl. Microbiol. 1986, 8, 75-79. [CrossRef]

34. Cline, S.W.; Doolittle, W.F. Transformation of members of the genus Haloarcula with shuttle vectors based on Halobacterium halobium and Haloferax volcanii plasmid replicons. J. Bacteriol. 1992, 174, 1076-1080. [CrossRef] [PubMed]

35. Lynch, E.A.; Langille, M.G.I.; Darling, A.; Wilbanks, E.G.; Haltiner, C.; Shao, K.S.Y.; Starr, M.O.; Teiling, C.; Harkins, T.T.; Edwards, R.A.; et al. Sequencing of Seven Haloarchaeal Genomes Reveals Patterns of Genomic Flux. PLoS ONE 2012, 7, e41389. [CrossRef] [PubMed]

36. Dyall-Smith, M. The Halohandbook: Protocols for haloarchaeal genetics. Halohandb. Protoc. haloarchaeal Genet. 2009, 1-144. Available online: https:/ / haloarchaea.com/wp-content/uploads/2018/10/Halohandbook_2009_v7.3mds.pdf (accessed on 21 January 2021).

37. Allers, T.; Ngo, H.-P.; Mevarech, M.; Lloyd, R.G. Development of Additional Selectable Markers for the Halophilic Archaeon Haloferax volcanii Based on the leuB and trpA Genes. Appl. Environ. Microbiol. 2004, 70, 943-953. [CrossRef]

38. Nuttall, S.D.; Smith, M.L.D. HF1 and HF2: Novel bacteriophages of halophilic archaea. Virology 1993, 197, 678-684. [CrossRef]

39. Schneider, C.A.; Rasband, W.S.; Eliceiri, K.W. NIH Image to ImageJ: 25 years of image analysis. Nat. Methods 2012, 9, 671-675. [CrossRef]

40. Schindelin, J.; Arganda-Carreras, I.; Frise, E.; Kaynig, V.; Longair, M.; Pietzsch, T.; Preibisch, S.; Rueden, C.; Saalfeld, S.; Schmid, B.; et al. Fiji: An open-source platform for biological-image analysis. Nat. Methods 2012, 9, 676-682. [CrossRef]

41. Ducret, A.; Quardokus, E.M.; Brun, Y.V. MicrobeJ, a tool for high throughput bacterial cell detection and quantitative analysis. Nat. Microbiol. 2016, 1, 1-7. [CrossRef] [PubMed]

42. Tittes, C.; Schwarzer, S.; Pfeiffer, F.; Dyall-Smith, M.; Rodriguez-Franco, M.; Oksanen, H.M.; Quax, T.E.F. Cellular and genomic properties of Haloferax gibbonsii LR2-5, the host of euryarchaeal virus HFTV1. bioRxiv 2020. [CrossRef]

43. Adler, J. Chemotaxis in bacteria. Science 1966, 153, 708-716. [CrossRef]

44. Esquivel, R.N.; Xu, R.; Pohlschroder, M. Novel archaeal adhesion pilins with a conserved N terminus. J. Bacteriol. 2013, 195, 3808-3818. [CrossRef]

45. Esquivel, R.N.; Schulze, S.; Xu, R.; Hippler, M.; Pohlschroder, M. Identification of Haloferax volcanii Pilin N-Glycans with Diverse Roles in Pilus Biosynthesis, Adhesion, and Microcolony Formation. J. Biol. Chem. 2016, 291, 10602-10614. [CrossRef]

46. Liao, Y.; Ithurbide, S.; Löwe, J.; Duggin, I.G. Two FtsZ proteins orchestrate archaeal cell division through distinct functions in ring assembly and constriction. bioRxiv 2020. [CrossRef]

47. Powell, M.S.; Slater, N.K.H. Removal rates of bacterial cells from glass surfaces by fluid shear. Biotechnol. Bioeng. 1982, 24, 2527-2537. [CrossRef] [PubMed]

48. Young, K.D. The Selective Value of Bacterial Shape. Microbiol. Mol. Biol. Rev. 2006, 70, 660-703. [CrossRef] [PubMed] 